\title{
Liver regeneration in relationship to acute liver failure
}

\author{
C D Gove, R D Hughes
}

In liver disease liver cell growth and repair are central processes in the recovery of normal structure and function. In acute liver failure where greater than $80 \%$ of the liver cell mass is destroyed by drugs or viruses ${ }^{1}$ complete regeneration of a normal liver occurs in surviving patients. In contrast the insidious cell loss found in chronic viral, alcoholic, and autoimmune disease is frequently not balanced by adequate cell replacement and coupled with a disruption of the hepatic architecture eventually leads to death from liver insufficiency. In spite of a vast literature on liver regeneration and hepatotrophic factors a clear understanding of how hepatic growth is controlled has not emerged.

The majority of in vivo studies have focused on the partially hepatectomised rat where liver regeneration is initiated within a few hours of surgery, with rapid cell division over the first four days, and liver size restored within two to three weeks. ${ }^{2}$ Less information is available in man but recovery is generally uncomplicated when resection is carried out in a previously healthy liver either to control bleeding after trauma or for a localised tumour. ${ }^{3}$ Evidence from serial liver scans, liver biopsies and repeated laparotomy indicates that regeneration is initiated within three days and complete after about six months. ${ }^{3}$

\section{Is liver regeneration inhibited in acute liver failure?}

Survival in fulminant hepatic failure is ultimately dependent on regeneration of an adequate functioning liver cell mass, although the development of severe complications, such as cerebral oedema $^{4}$ and bacterial ${ }^{5}$ and fungal sepsis, ${ }^{6}$ also have a major influence on outcome. In spite of a massive apparent loss of viable hepatocytes and extensive reduction in reticuloendothelial system function restoration of the different liver functions occurs rapidly in surviving fulminant hepatic failure patients and approaches normal within 10 days $^{7}$ - namely, synthetic capacity, as evidenced by the prothrombin time, metabolic capacity, assessed by galactose elimination, and removal of particulate material, as determined by clearance of microaggregated albumin. In spite of an overall increase in survival in fulminant hepatic failure mainly through improved intensive care treatment regimens certain aetiological groups, fulminant hepatic failure as a result of non-A non-B hepatitis and adverse reactions to drugs, still have a poor survival. ${ }^{8}$ This has been attributed to a lack of liver regeneration, ${ }^{9}$ however, an alternative explanation for this, particularly in cases where the illness has a long course, may be that regeneration occurs but continued hepatocyte injury exceeds the rate of the repair process. This may lead to a situation where there is histological evidence of liver regeneration without recovery of liver function. Some support for this view has been obtained by comparing liver regeneration, assessed from the mitotic index and the presence of polyploid DNA in liver nuclei, in fatal liver failure with that in uncomplicated hepatitis. The response was found to be similar, suggesting the rate of liver cell necrosis was the important factor in determining outcome, however, in the absence of data from surviving fulminant hepatic failure patients the significance of these results is difficult to interpret. ${ }^{10}$ If hepatocyte loss is too great then insufficient liver tissue may remain for recovery. In an early study, the hepatocyte volume fraction was less than $12 \%$ in all but one of 17 patients where the cause of death was attributed to liver failure alone." Studies in rats have revealed that there is a hepatic energy charge threshold below which regeneration ceases as the energy demands of other metabolic processes, including gluconeogenesis and the urea cycle, take precedence. ${ }^{12}$ Decreased hepatic energy charge has been suggested to be the cause of liver insufficiency after major hepatic resection. ${ }^{13}$ An assessment of hepatic energy charge can be made from the arterial ketone body ratio because the ratio of [acetoacetate]/[ $\beta$-hydroxybutyrate] diffusing out of the hepatocytes reflects the mitochondrial adenylate energy charge, ${ }^{14}$ and this has been used in patients undergoing hepatic resection to successfully predict their postoperative prognosis. ${ }^{15}$ In patients with fulminant hepatic failure seen on the King's Liver Unit the ketone body ratio was found to be considerably lower than in control patients with normal liver function. ${ }^{16}$ On admission the ketone body ratio was lower in fulminant hepatic failure patients who ultimately died than in those who survived and continued to decrease throughout their illness. ${ }^{16}$ Survival of rats after subtotal hepatectomy $(90 \%)$, provided access to $20 \%$ glucose in the drinking water was maintained, suggests that $10 \%$ of functioning liver mass is adequate to ensure regeneration. ${ }^{17}$ The preferred energy substrate alters in the regenerating liver, ${ }^{18}$ however, and infusion of high concentrations of glucose can be inhibitory as a result of reduced energy charge consequential upon inhibition of lipolysis.

Three distinct processes have been identified in the control of hepatic growth. Early events in the initiation of regeneration are independent of protein synthesis and involve the rapid activation of a number transcriptional regulators such as cjun, c-myc and c-fos. ${ }^{19}$ Later initiating events are
King's College School of Medicine and Dentistry, 
sensitive to inhibitors of translation - for example, the increase in the activity of ornithine decarboxylase, which is involved in the synthesis of polyamines which stabilise mRNA. ${ }^{20}$ Once regeneration is initiated an optimal response is promoted by a variety of trophic factors including growth factors - for example, epidermal growth factor, ${ }^{21} \mathrm{TGF} \alpha,{ }^{22}$ and hormones such as insulin and glucagon. ${ }^{23}$ Finally growth seems to be limited by inhibitors or chalones such as $\mathrm{HPI}^{24}$ and TGF $\beta$, ${ }^{25}$ although much less work has been carried out in this area than in the field of growth stimulation.

Considerable effort has been made to isolate and characterise the specific hepatic regenerative stimulator substances from animals and man, including from serum of patients with liver failure.$^{26}$ The possibility is emerging that in fulminant hepatic failure an adequate response to liver cell loss, in terms of production of stimulatory factors occurs, but toxic substances present, as a result of release from the necrotic hepatic remnant and lack of detoxification of substances from the gut, inhibit or delay liver regeneration and the recovery of hepatic function.

\section{Evidence for inhibitors of hepatic regeneration} in acute liver failure

Early work in the King's Liver Unit and elsewhere revealed direct toxicity of plasma from fulminant hepatic failure patients to rabbit $^{27}$ and $\mathrm{rat}^{28}$ hepatocytes in monolayer culture after prolonged exposure. The effects with rabbit hepatocytes were highly potent, being apparent at 1 in 5 dilution of the plasma, and toxicity could be reduced but not eliminated by heating. When the acute effects of fulminant hepatic failure serum were examined in hepatocytes freshly isolated from both normal rat livers and $24 \mathrm{~h}$ after partial hepatectomy differences in response were found between the two types of cells. DNA and protein synthesis was accelerated in hepatocytes from regenerating livers to a similar extent to that observed in vivo. A specific inhibitory effect on DNA synthesis with fulminant hepatic failure serum but not with normal serum was found in regenerating hepatocytes. DNA and protein synthesis in normal hepatocytes was inhibited by normal serum, the inhibition being less with fulminant hepatic failure serum. ${ }^{29}$ Cell integrity was not affected in these short incubations suggesting that cytotoxicity may take longer to develop. The differences in response to fulminant hepatic failure serum of DNA synthesis in normal and regenerating hepatocytes may either be a reflection of increased sensitivity of the regenerating hepatocyte to toxic substances or the greater ability of normal hepatocytes to detoxify these substances. The decrease in DNA and protein synthesis in normal hepatocytes in the presence of normal serum supports the hypothesis that liver size may be regulated by substances inhibitory to liver cell growth which are present in normal serum, the concentration(s) of which fall(s) with hepatocyte loss or damage. The less inhibitory effect of fulminant hepatic failure serum compared with normal serum in the normal cells may reflect a reduction in the concentration of these substances or the additional presence of stimulatory factor(s). Under suitable conditions stimulation of DNA synthesis by fulminant hepatic failure serum, compared with normal serum, has been shown in cultured rat hepatocytes. ${ }^{30}$ The presence of stimulatory and inhibitory factors in fulminant hepatic failure serum, perhaps with varying relative concentrations at different stages of the illness, may be an explanation for these different observations. Alternatively, differences in culture conditions or relative differentiation of the hepatocytes may be responsible.

The complex process of liver regeneration in vivo also involves interaction between cells in the intact liver with an undisturbed architecture ${ }^{31}$ and with a wide range of physiological and humoral factors which cannot be reproduced in vitro. Whole animal experiments have therefore been undertaken in an attempt to establish the relevance of the observations in isolated cells. ${ }^{32}$ Rats were injected with fulminant hepatic failure or normal serum over a three hour period either immediately or $20 \mathrm{~h}$ after partial hepatectomy. DNA synthesis was determined at $24 \mathrm{~h}$ post partial hepatectomy from the incorporation of ${ }^{3} \mathrm{H}$-thymidine into extracted and purified DNA. Hepatic DNA synthesis showed a 16-fold acceleration $24 \mathrm{~h}$ after partial hepatectomy compared with the rate in unoperated control animals. Fulminant hepatic failure serum inhibited DNA synthesis acutely (late injection, $20-23 \mathrm{~h}$ ) in partially hepatectomised rats but had no effect when injected early. Thus fulminant hepatic failure serum did not affect the initiation of regeneration. Serum was fractionated by ultrafiltration, using a $10 \mathrm{kD}$ cut off membrane, in a simple attempt to separate stimulatory activity from possible inhibitors, because most reports to date indicate that hepatic growth stimulatory peptides in human serum have molecular weights $>10 \mathrm{kD}$. Late injection of the $<10 \mathrm{kD}$ fraction caused significant inhibition of DNA synthesis in regenerating livers compared with non-injected controls and those receiving the equivalent fraction from normal serum. On the other hand when the $>10 \mathrm{kD}$ fraction was tested no evidence of stimulation was found. It would seem unlikely that stimulatory factors were absent from these preparations as hepatocyte growth factor has been reported to be raised in the plasma of patients with fulminant hepatic failure (see section below). One explanation may be that protein bound low molecular weight inhibitors counteracted any stimulatory activity.

Unlike the observations with freshly isolated hepatocytes in vitro normal serum acutely inhibited DNA synthesis in regenerating livers in vivo. Fractionation of normal serum abolished the inhibition, in contrast with fulminant hepatic failure serum, implying that the synergistic action of different molecular weight inhibitors may be involved and that different inhibitors may be present in the two sera. This is consistent with the possible presence of chalones in normal serum.

In summary, close examination of the evidence suggests that stimulatory substances are probably present in the circulation in fulminant hepatic failure but that unidentified 
inhibitory substances may counteract their effects.

To further characterise the nature of the inhibitory factors experiments have been performed using rat hepatocytes in primary culture in the presence of epidermal growth factor and insulin. ${ }^{33}$ Fulminant hepatic failure serum ultrafiltrates $(<10 \mathrm{kD})$ significantly inhibited incorporation of ${ }^{3} \mathrm{H}$-thymidine into DNA to $2 \cdot 7 \% \mathrm{SD}$ $(4 \cdot 7) \%$ of control value. This effect was dose dependent, reversible and was not associated with an increase in lactate dehydrogenase release. Column chromatography on Sephadex G-25 gel produced two peaks of inhibitory activity corresponding to apparent molecular weights of $2 \mathrm{kD}$ and $5 \mathrm{kD}$. Possible interaction of small lipophilic molecules with the dextran gel could cause retardation and lead to elution at a position corresponding to a greater molecular size.

\section{Identity of the inhibitory substances}

While the identity of the factors responsible for the inhibitory effects is not known there are a number of groups of substances which could be involved. It seems unlikely that 'endogenous' inhibitors of liver cell growth, whose role is to limit liver growth to normal size, would be secreted or activated inappropriately, although the release of sequestered pools from necrotic liver tissue remains a possibility.

One of the characteristic features of liver failure is the accumulation of a wide range of toxic substances in the circulation. These may interfere directly with the process of liver regeneration or indirectly through effects on energy metabolism as discussed earlier. Zeive et al have performed a number of studies with ammonia, octanoate, and mercaptans which are known to accumulate in liver failure and have also been shown to have toxic effects in the brain. Liver thymidine kinase activity and the incorporation of ${ }^{3} \mathrm{H}$-thymidine into hepatic DNA were depressed after repeated injection of these compounds into rats after partial hepatectomy. ${ }^{34}$ The effects were reversible but the mechanisms involved were not investigated. In further experiments the effects of these toxins were studied with liver injury caused by acetaminophen ${ }^{35}$ and galactosamine. ${ }^{36}$ Greater depression of hepatic thymidine kinase and ornithine decarboxylase activities was seen after centrilobular damage from paracetamol.

A number of the inflammatory mediators and cytokines produced by monocytes and macrophages in response to stimulation by endotoxin have been shown to affect DNA synthesis. Patients with acute liver failure frequently develop bacterial infections ${ }^{5}$ with increased release and production of cytokines including tumour necrosis factor. The dose dependent effects of interleukins 1,2 and 6 (IL-1, IL-2, IL-6) on DNA synthesis in adult rat hepatocytes in primary culture stimulated by insulin and epidermal growth factor have been investigated. ${ }^{37}$ Significant inhibition of DNA synthesis by IL-1 and to a lesser extent IL-6, but not IL-2 or tumour necrosis factor was found. IL-1 production $^{38}$ and serum IL-6 concentration ${ }^{39}$ have been shown to be significantly increased in patients with liver failure, suggesting their possible importance in influencing liver regeneration in this condition. These cytokines may be responsible for counteracting the effects of stimulatory substances in the $>10 \mathrm{kD}$ fraction as is suggested by the in vitro and in vivo experiments, as discussed above, as their molecular weights are $17 \mathrm{kD}$ to $22 \mathrm{kD}$ respectively. They would not appear in the 'toxic' $<10 \mathrm{kD}$ ultrafiltrate fraction of fulminant hepatic failure serum, however, which had the acute direct inhibitory effects on DNA synthesis in these experiments.

\section{Hepatocyte growth factor}

One of the most recent significant developments has been the purification and characterisation of hepatocyte growth factor. Three independent groups, two from Japan and one from the USA have isolated hepatocyte growth factor from different sources. Hepatocyte growth factor is species non-specific and substances with a similar structure have been purified from rat platelets, ${ }^{40}$ rabbit serum and normal human plasma $^{41}$ and plasma from patients with fulminant hepatic failure. ${ }^{42}$ The human material (hHGF) is a heterodimer with molecular weight ranging between $79 \mathrm{kD}$ to $86 \mathrm{kD}$ and consists of two polypeptide chains, heavy and light, linked together by disulphide bonds. Hepatocyte growth factor is a heparin binding growth factor and is distinct from other known hepatocyte growth factors such as insulin, epidermal growth factor and TGF $\alpha$. It is the most potent mitogen for hepatocytes in primary culture and has synergistic effects with insulin, glucagon and epidermal growth factor. Using molecular cloning techniques it has been possible to obtain the nucleotide sequence of hHGF by cloning hepatocyte growth factor cDNA and thus deduce its aminoacid structure. ${ }^{434}$ There is considerable homology of hepatocyte growth factor with serine proteases, particularly plasminogen, but the significance of this is unknown.

With biological and ELISA assays, it was shown that the blood concentrations of hepatocyte growth factor are increased in patients with fulminant hepatic failure with the highest levels being found in patients with deep encephalopathy and those who died. This suggests that the stimulus to liver regeneration may be adequate, but the response is impaired. The next step is to isolate and characterise hHGF receptors and define the intracellular processes which lead to promotion of hepatocyte DNA synthesis and cell division. It is possible that these mechanisms are disrupted in patients with fulminant hepatic failure. With the availability of pure recombinant hHGF it will be important to perform in vivo experiments on the stimulatory effects of hepatocyte growth factor on hepatic DNA synthesis, as to date all data have been obtained using hepatocyte culture. This will be essential to evaluate the therapeutic potential of hepatocyte growth factor, as a hepatotrophic treatment in patients with liver failure.

The site of production of hepatocyte growth factor is fundamental to the understanding of its function. A number of studies have been performed on this using either immunochemical 
techniques, Northern blotting or in situ hybridisation and the results may have been influenced by the method used. Different sites other than the liver have been identified which seem to vary according to the nature of the liver injury and the species studied and include the spleen, lung, brain and kidney. In the light of number of tissues synthesising hepatocyte growth factor, it is likely that it may affect other epithelial cells than those in the liver. From experiments in rats with liver injury caused by galactosamine or carbon tetrachloride the non-parenchymal cells in the liver, particularly the Kupffer cells appear to be the main site of hepatocyte growth factor synthesis, consistent with a paracrine mechanism of hepatocyte growth factor action. ${ }^{45}$ As yet no equivalent information on the site of hepatocyte growth factor production has been obtained in man.

Although hepatocyte growth factor is the most potent hepatocyte growth factor it is not clear if other factors are required for the process of liver regeneration. The hepatic stimulatory effects of another novel growth factor, which appears to be bilirubin covalently bound to serum albumin (biliprotein), have been reported. ${ }^{46}$ The plasma levels of this complex were investigated in patients during the course of fulminant hepatic failure. Biliprotein levels expressed as a percentage of total bilirubin were significantly higher on admission and rose subsequently in patients who survived compared with those who died. ${ }^{47}$ The role of biliprotein in the recovery of liver function needs to be further elucidated.

\section{Future directions}

Liver regeneration is clearly under multifactorial control throughout all stages. The initial signal which starts the process remains to be identified, although there is still the possibility that it may simply be a response to increased metabolic demand in the remaining tissue. Compensatory growth in small livers grafted into large recipients has been shown for $\operatorname{dogs}^{48}$ and humans. ${ }^{49}$ The true role of stimulator substances in the in vivo situation remains unclear. They are able to initiate the regenerative response in normal animals and cultured cells but do not appear immediately in vivo after a reduction in hepatocellular mass as a result of surgery or toxic insult. Hepatocyte growth factor mRNA starts to increase about five hours after liver damage in rats reaching a maximum around $10 \mathrm{~h},{ }^{50}$ while ornithine decarboxylase activity is increased $1 \mathrm{~h}$ post partial hepatectomy and reaches a peak at about four hours. ${ }^{51}$ The main role of stimulator substances may therefore be to amplify the response once started.

One of the earliest events involves the transcriptional activation of immediate early genes, and is reliant upon the activation of transcription factors already present in the cells. This is followed by activation of a number of other cell cycle dependent genes some of which have been identified..$^{52}$ Further identification of other genes which are activated during liver regeneration and analysis of stage specificity will aid in understanding control processes.

The coordination between the different cell populations within the regenerating organ, leading to the re-establishment of normal architecture and function, must involve cell-cell communication through surface contact and/or signal molecules. Kupffer cells, particularly, may have an important role in controlling liver regeneration, not only have they been shown to influence hepatocyte metabolic activity ${ }^{53}$ but also to modify the response to insult, ${ }^{545}$ which may be of relevance in fulminant hepatic failure where ongoing damage may be occurring. Non-parenchymal cells are also the main site of production of interleukins and hepatocyte growth factor within the liver. One major difference between liver regeneration in fulminant hepatic failure and partial hepatectomy is the inflammatory component, and it is important to take this into account in experimental studies.

During embryogenesis and development the establishment of hepatic architecture and cell populations is uncomplicated by existing mature structures as occurs in the regeneration of a damaged liver. An understanding of the tissue induction and growth control processes during normal organogenesis should help identify important control points which may also be involved in liver regeneration in the adult, and shed light on the development of abnormal structure in cirrhosis where there is evidence of stimulation of regrowth in the regenerating nodules but there is a failure to establish normal architecture.

Identification and characterisation of the inhibitory factors present in the circulation in acute liver failure will also help in understanding how liver growth and regeneration is controlled.

In fulminant hepatic failure the increased circulating concentrations of stimulator substances which have been described imply that liver regeneration is already initiated. In at least some groups of patients, and possibly all, there is evidence that liver regeneration is delayed or that an adequate regenerative response does not occur. Whether infusion of recombinant hHGF and/or other stimulator substances will improve the response in these patients remains to be seen.

An alternative approach to the treatment of liver failure is the use of heterotopic liver transplantation or the use of extracorporeal 'hepatocyte reactors' to provide temporary liver support while the patient's own liver recovers. The presence of an intact functioning liver, or equivalent hepatocyte mass, could possibly reduce the regenerative response in the host organ. The relationship between the host and donor liver will provide further insight into the control mechanisms involved in liver regeneration.

1 Ranek L, Andreasen B, Tygstrup N. Galactosamine elimination capacity as a prognostic index in patients with fulminant hepatic failure. Gut 1980; 17: 959-64.

2 Higgins GM, Anderson RM. Experimental pathology of the liver. I. Restoration of the liver of the white rat following partial surgical removal. A M A Arch Pathol 1932; 12: 186202.

3 Lin TY, Lee CS, Chen CC, Liau KY, Lin WS. Regeneration of human liver after hepatic lobectomy studied by repeated liver scanning and repeated needle biopsy. Ann Surg 1979; liver scanning $48-50$.

4 Ede RJ, Williams R. Hepatic encephalopathy and cerebral edema. Semin Liver Dis 1986; 6: 107-18.

5 Rolando N, Harvey F, Brahm J, et al. Prospective study of bacterial infection in acute liver failure: An analysis of fifty patients. Hepatology 1990; 11: 49-53. 
6 Rolando N, Harvey F, Brahm J, et al. Fungal infection - a common, unrecognised complication of acute liver failure. f Hepatol 1991; 12: 1-9.

7 Canalese J, Gove CD, Gimson AES, Wilkinson SP, Wardle EN, Williams R. Reticuloendothelial system and hepatocyte EN, Williams R. Reticuloendothelial system and hepatocyte

8 O'Grady JG, Alexander GJM, Hayllar KM, Williams R. Early indicators of prognosis in fulminant hepatic failure. Gastroenterology 1989; $97:$ : 439-45.

9 Rakela J, Lange SM, Ludwig J. Baldus WP. Fulminant hepatitis: Mayo Clinic experience with 34 cases. Mayo Clin Proc 1985; 60: 289-92.

10 Milandri M, Gaub J, Ranek L. Evidence for liver cell proliferation during fatal acute liver failure. Gut 1980; 21: 423-7.

11 Gazzard BG, Portmann B, Murray-Lyon IM, Williams R. Causes of death in fulminant hepatic failure and relationship to quantitative assessment of parenchymal damage. $Q \mathcal{F} M$ ed to quantitative assess

12 Ozawa K, Yamada T, Ukikusa M, et al. Mitochondrial phosphorylative activity and DNA synthesis in regenerating liver of diabetic rats. F Surg Res 1981; 31: 38-45.

13 Ozawa K, Kamiyama Y, Ukikusa M, Tobe T. Significance of hepatic energy charge and blood ketone body ratio as criteria of liver support. Indication and efficiency in hepatectomised patients during crossed dialysis. In: Brunner G, Schmidt FW, eds. Artificial liver support. Berlin: Springer Verlag, 1981: 164-9.

14 Ozawa K, Yamaoka Y, Kimura K, et al. Circulating hepatodepressant factors decreasing energy charge levels of the remnant liver after hepatectomy. Eur Surg Res 1981; 13: 4444-57.

15 Asano M, Ozawa $\mathrm{K}$, Tobe $\mathrm{T}$. Postoperative prognosis as related to blood ketone body ratios in hepatectomised patients. Eur Surg Res 1983; 15: 302-1

16 Saiola A, MacMathuna P, Langley PG, Gove CD, Hughes $\mathrm{RD}$, Williams R. Determination of the ketone body ratio in fulminant hepatic failure. Hepatogastroenterology 1990; 37: 413-6.

17 Gaub J, Iversen J. Rat liver regeneration after $90 \%$ partial hepatectomy. Hepatol 1984; 4: 902-4.

18 Nakatani T, Yasuda K, Ozawa K, Kawashima S, Tobe T Effects of (+)-octanoylcarnitine on deoxyribonucleic acid
synthesis in regenerating rabbit liver. Clin $\mathrm{Sci}$ 1982; 62: 295-97.

19 Morello D, Fitzgerald MJ, Babinet C, Fausto N. c-myc, c-fos and $c$-jun regulation in the regenerating liver of normal an H-2K/c-myc transgenic mice. Mol Cell Biol 1990; 10: 3185 93.

20 Friedman JM, Chung EG, Darnell JE. Gene expression during liver regeneration. $7 \mathrm{Mol} \mathrm{Biol} \mathrm{1984;} \mathrm{179;} \mathrm{37-53.}$

21 Raper SE, Burwen SJ, Barker ME, Jones AL. Translocation of epidermal growth factor to the hepatocyte nucleus during liver regeneration. Gastoenterology 1987; 92: 1243-50.

22 Mead JE, Fausto N. Transforming growth factor TGF $\alpha$ may be a physiological regulator of liver regeneration by means of an autocrine mechanism. Proc Natl Acad Sci 1989; 86: an autocrine

23 Bucher NRL, Swaffield MN. Regulation of hepatic regeneration in rats by synergistic action of insulin and glucagon Proc Natl Acad Sci 1975; 72: 1157-60.

24 MacMahon JB, Type P. Specific inhibition of proliferation of non-malignant rat hepatic cells by a factor from the rat liver. Cancer Res 1980; 40: 1249-54.

25 Russell WE, Coffey JR, Ouellette AJ, Moses HL. Type beta transforming growth factor reversibly inhibits the early proliferative response to partial hepa

26 Gohda E, Tsubouchi H, Nakayama H, et al. Human hepatocyte growth factor in plasma from patients with fulminant hepatic failure. Exp Cell Res 1986; 166: 139-50.

27 Hughes RD, Cochrane MG, Thompson AD, Murray-Lyon IM, Williams R. The cytotoxicity of plasma from patient with acute hepatic failure to isolated rabbit hepatocytes. $\operatorname{Br} \mathcal{F}$ Exp Pathol 1976; 57: 348-53.

28 Haas Th, Holloway CJ, Osterthun V, Trautschold I. Hepatotoxic effects of sera from patients with fulminant hepatitis B on isolated rat hepatocytes in culture. $\mathcal{F}$ Clin Chem Clin Biochem 1981; 19: 283-6.

29 Gove CD, Hughes RD, Williams R. Rapid inhibition of DNA synthesis in hepatocytes from regenerating livers by serum from patients with fulminant hepatic failure. $B r \neq E x p$ Prom patients with fulm

30 Nakayama H, Tsubouchi $\mathrm{H}$, Gohda E, et al. Stimulation of DNA synthesis in adult rat hepatocytes in primary culture by sera from patients with fulminant hepatic failure. Biomedical Res 1985; 6: 231-7.
31 Meyer DJ, Yancey SB, Revel J-P. Intercellular communication in normal and regenerating rat liver: a quantitative analysis. F Cell Biol 1981; 91: 505-23.

32 Yamada $H$, Gove CD, Hughes RD, Williams R. Effects of fulminant hepatic failure serum on hepatic DNA synthesis in normal and partially hepatect

33 Yamada H, Toda G, Ikeda Y, Kurokawa K, Hughes RD, Williams $R$. Occurence of inhibitors of in vivo and in vitro DNA synthesis in rat hepatocytes in fulminant hepatic failure serum. [Abstract] Hepatology 1990; 12: 916.

34 Zeive L, Shekelton M, Lytfogt C, Draves K. Ammonia, octanoate and a mercaptan depress regeneration of normal
rat liver after partial hepatectomy. Hepatology 1985; 5: rat liver

35 Zeive L, Dozeman R, LaFontaine D. Effect of hepatic failure toxins on liver thymidine kinase activity and ornithine decarboxylase activity after massive necrosis with acetaminophen in the rat. $\mathcal{~ L a b ~ C l i n ~ M e d ~ 1 9 8 5 ; ~ 1 0 6 : ~ 5 8 3 - 8 . ~}$

36 Zeive L, Dozeman R. Effect of hepatic failure toxins on regenerative enzymes in the liver after injury with galactosamine in the rat. $₹$ Lab Clin Med 1989; 113: 463-8.

37 Nakamura T, Arakaki R, Ichihara A. Interleukin- $1 \beta$ is a potent growth inhibitor of adult rat hepatocytes in primary culture. Exp Cell Res 1988; 179: 488-97.

38 Muto Y, Nouri-Aria KT, Meager A, Alexander GJM, Eddleston ALWF, Williams R. Enhanced tumour necrosis factor and interleukin-1 in fulminant hepatic failure. Lancet 1988; ii: $72-4$.

39 Sheron N, Goka J, Wendon J, et al. Highly elevated plasma cytokines in fulminant hepatic failure: correlations with multiorgan failure and death. Hepatology 1990; 12: 939 .

40 Nakamura T, Nawa K, Ichihara A, Kaise N, Nishino T. Purification and subunit structure of hepatocyte growth factor from rat platelets. Febs Lett 1987; 224: 311-6.

41 Zarnegar R, Michalopoulos G. Purification and biological characterization of human hepatopoietin A, a polypeptide growth factor for hepatocytes. Cancer Res 1989; 49: 3314-20.

42 Gohda E, Tsubouchi H, Nakayama $\mathrm{H}$, et al. Purification and partial characterization of hepatocyte growth factor from
plasma of a patient with fulminant hepatic failure. $₹$ Clin plasma of a patient with

43 Nakamura T, Nishizawa T, Hagiya $M$, et al Molecular cloning and expression of hepatocyte growth factor. Nature 1989 342: 440-3.

44 Miyazawa K, Tsubouchi H, Naka D, et al. Molecular cloning and sequence analysis of cDNA for human hepatocyte growth factor. Biochem Biophys Res Commun 1989; 163: 967-73.

45 Noji S, Tashiro K, Koyama E, et al. Expression of hepatocyte growth factor gene in endothelial and Kupffer cells of growth factor gene in endothelial and Kupffer cells of Biochem Biophys Res Commun 1990; 173: 42-7.

46 Diaz-Gil JJ, Gavilanes JG, Garcia-Canero R, et al. Liver growth factor purified from human plasma is an albuminbilirubin complex. Mol Biol Med 1989; 6: 197-207.

47 Zhang L, Hughes RD, Williams R. Determination of plasm biliprotein levels in patients with fulminant hepatic failure. [Abstract] Gut 1990; 31: A1210.

48 Kam I, Lynch S, Svanas G, et al. Evidence that host size determines liver size: studies in dogs receiving orthotopic liver transplants. Hepatology 1987; 7: 362-6.

49 Van Thiel DH, Gavaler JS, Kam I, et al. Rapid growth of an intact human liver transplanted into a recipient larger than intact human liver transplanted into a recipient

50 Kinoshita T, Tashiro K, Nakamura T. Marked increase of HGF mRNA in non-parenchymal liver cells of rats treated with hepatotoxins. Biochem Biophys Res Comm 1989; 165: 1229-34.

51 Wondergem R, Potter VR. A new protocol for studying the early events during liver regeneration. Life Sci 1978; 23 . 1565-76.

52 Biesiada E, Chorazy M. Expression of "cell-cycle-dependent" genes in regenerating rat liver. Cell Biol Int Reports 1988; 12: 483-92.

53 West MA, Billiar TR, Curran RD, Hyland BJ, Simmonds RL. Evidence that rat Kupffer cells stimulate and inhibit hepatocyte protein synthesis in vitro by different mechanisms. cyte protein synthesis in vitro by
Gastroenterology 1989; $96: 1572-82$.

54 Holper K, Olcay I, Kitahama A, et al. Effect of ischaemia on hepatic parenchymal and reticuloendothelial function in the hepatic parenchymal and reticuloend

55 Grun M, Liehr H, Grun W, Rosenack U, Brunsnig D. Influence of liver RES on toxic liver cell damage due to galactosamine. Acta Hepatogastroenterol 1974; 21 : 5-15. 